glass-phial crusher was described for use with the equipment.

The next speaker, Mr. J. R. Bishop, discussed the use of directly heated bead thermistors in thermal conductivity detectors. He presented data on the sensitivity of five different types of elements of both British and American manufacture. Using nitrogen as carrier gas, $S$ values of 100-600 had been obtained with noise level lower than 10 microvolts. All types examined are stable up to $150-160^{\circ} \mathrm{C}$. in nitrogen but with hydrogen as carrier gas the upper limit is only $100^{\circ} \mathrm{C}$. at low bridge currents. With a bridge current of 15 milliamp. in hydrogen, noise appears, especially with uncoated beads, and at higher currents irreversible changes take place. A simple arrangement with a single thermistor supported in an extension $8 \mathrm{~mm}$. in diameter at the end of a glass chromatographic column is effective and has a low detector volume. It is inherently sensitive to flow and this is best compensated by using another thermistor in the bridge, placed at the end of a second column. With the two elements connected in parallel to the applied voltage it was shown that the sensitivity was highest when the two fixed bridge resistors had values lower than the operating resistance of the thermistors. A detector with four thermistors connected in a bridge, which should give even higher sensitivity, was being constructed. Mr. Bishop directed attention to new American thermistors capable of operation up to $300^{\circ}$ C., and illustrated the robustness of modern elements by describing how a colleague regularly cleans his detector with strong sulphuric acid. In conclusion, he commented on the possible use of thermistors for vapour detection based on specific heat rather than thermal conductivity differences.

One of the most recent detectors described, the low-pressure electric discharge, formed the subject of the last paper, by Dr. R. C. Pitkethly. Preliminary experiments with simple discharge tubes similar in construction to that used by Harley and Pretorius ${ }^{5}$ demonstrated the very high sensitivity of the voltage drop across the discharge to small changes in concentration of hydrocarbon vapours in a stream of nitrogen passing through it. Early tubes, with platinum electrodes spaced a few centimetres apart, were very noisy and showed a poor linearity of response, with tailing of the peaks. These effects were attributed to electrode sputtering, changes in the number of bands in the positive column, poor scavenging and pronounced pressure sensitivity. An improved detector tube, employing a modified small neon indicator bulb, had been developed. This had comparatively large closely spaced iron electrodes, and was run at a pressure of about $3 \mathrm{~mm}$. mercury with 200 $300 \mathrm{~V}$. across it. A pair of these tubes were connected to the ends of two columns with fine capillary tube, which provided the necessary pressure drop. They were operated in a simple bridge circuit with a double triode impedance changer to enable a standard highspeed potentiometric recorder to be employed. With this arrangement operated at room temperature, it is easily possible to detect a concentration of paraffin hydrocarbon gases in nitrogen of one part in ten million by volume. In the range $\mathrm{C}_{3}-\mathrm{C}_{8}$, the response to paraffins eluted in nitrogen from a column ranged from 9 to 38 volt-litres per micromole, rising with molecular weight. This sensitivity in the units proposed earlier is of the order of $3 \times 10^{8} \mathrm{mV}$. ml./mgm. with a noise level of $20 \mathrm{mr}$.

Before closing the meeting, the chairman invited Mr. R. P. W. Scott to describe his recent work with the hydrogen flame detector. A miniature bunsen burner-like attachment had been fixed to the top of the jet, which produced a pre-mixed flame more compact and stable than the original diffusion type. This, in conjunction with a platinum-rhodium/ platinum thermocouple $0.004 \mathrm{in}$. in diameter on an improved support, had produced a marked increase in sensitivity. The minimum detectable concentration was now about $0.07 \mathrm{\gamma} / \mathrm{ml}$. with a signal to noise ratio of four.

D. H. Desty

"Vapour Phase Chromatography". Proceedings of a Symposium held in London, May 1956 (Butterworths, 1957).

${ }^{3}$ Dimbat, M., Porter, P. E., and Stross, F. H., Anal. Chem., 28, 290 (1956).

Deal, C. H., Otvos, J. W., Smith, V. N., and Zucco, P. S., Anal. Chem., 28, 1958 (1956).

- Breuner, A., Couch, D. E., and Williams, F. K., J. Res. Nat. Bur. Stand., 44, 109 (1950).

'Harley, N., and Pretorius, V., Nature, 178, 1244 (1956).

\section{TRACE ELEMENTS IN SOILS, PLANTS AND ANIMALS}

$M$

ORE than one hundred people listened with interest to papers and discussion at a symposium on trace elements in soils, plants and animals which was held in Bristol during April 10-12. Seven papers out of seventeen were contributed by workers at Long Ashton. C. Bould spoke on iron chelates for control of chlorosis in plants. With fruit trees, good results were obtained by applying chelates to the soil, provided that they were well watered in so that they reached the rooting zone before their iron was liberated by interaction with calcium. For strawberries or blackeurrants seasonal cure of chlorosis could be obtained by foliar sprays : a good wetting agent was essential. If chelates are absorbed in excess by plants there is a risk that minor elements may be affected. E. J. Hewitt reported that, with cauliflower, molybdenum is required not only for reduction of nitrate; when toxic accumulation of nitrate is avoided, by supplying nitrogen in other forms, deficiency of molybdenum has disturbing effects involving limited growth, reproductive failure and low concentration of ascorbic acid and, in cauliflower, symptoms of whiptail. In discussion it was mentioned that soil acidity, which is normally accompanied by lack of calcium, may cause plant injuries due to deficiency of molybdenum or excess of manganese and aluminium. D. J. D. Nicholas reported that in Neurospora and in green plants the step-wise reduction of nitrate to nitrite, to hyponitrite, to hydroxylamine, to ammonia was effected by flavin enzymes dependent on molybdenum, on copper and iron, on copper and iron, and on manganese, respectively. An alternative to the final step is the non-enzymic reaction of hydroxylamine with ketonic acids, resulting in the formation of oximes which are then reduced enzymically to aminoacids. That molybdenum is a constituent of nitrate reductase has been shown, because activity of the enzyme was diminished after dialysis in the presence of cyanide but was largely restored by adding molybdenum to the apoenzyme, whereas addition of various other elements was without effect. Strains of Azotobacter and Clostridium require molybdenum and iron for nitrogen fixation; in some instances vanadium or tungsten can replace molybdenum in this process. The hydrogenase enzyme, which is primarily irondependent, is not invariably coupled with nitrogen 
fixation. Speaking of tropical agriculture, R. A. Webb noted that preoccupation with the major plant nutrients, nitrogen, phosphorus and potassium, had led to neglect of other nutrients which are now known to be essential for satisfactory growth of plants. $\mathrm{He}$ had obtained decisive indications of several elementary deficiencies with pot experiments in the Gambia by using subtractive techniques developed at Long Ashton. Similar results were now being obtained in other tropical areas. Successful fertilizer practice might require the use of mixtures supplying four or more essential nutrients. In discussion the need was stressed for sound agronomic practices and for numerous and widely scattered field experiments.

A. H. Williams described an investigation of certain organic compounds in plants and their variation with nutritional status; it was hoped that in plants suffering from nutrient deficiencies accumulation might occur of metabolic intermediates not readily detected in normal plants. Using paper chromatography, he found unusually large amounts of arginine in cauliflowers grown at low molybdenum-levels and supplied with nitrogen sources other than nitrate; when nitrate was supplied a low content of glutamic acid accompanied molybdenum deficiency. With tomato there is evidence that several linked metabolic processes are dislocated by deficiency of potassium or calcium or magnesium; this was associated with high levels of asparagine and glutamine and marked changes in the contents of malic and nitric acids and sugars. In discussion, the bearing of these studies on animal nutrition was mentioned. H. M. Stevens described the use of paper chromatography in the separation of valency states of biologically important metals: the method was applied to the preparation of $f$ ure cation solutions in known valency states which were used to determine valency changes in metals during enzymic action. C. F. Timberlake had found small quantities of copper, zinc, iron and lead in the tissues of fruit and still less in fruit juice. Copper occurs in polyphenol oxidase, but also occurs in ionic association with malic acid and in more stable complexes with amino-acids and with many phenolic compounds. At acid $p \mathrm{H}$ values normally found in fruits, only a small proportion of copper may be complexed with phenolic compounds: it acts as catalyst during their oxidation. In discussion it was noted that organic acids give copper complexes that differ widely in their stability and presumably in their nutritive value.

M. Fieldes and N. Wells reported that in New Zealand the composition of sweet vernal grass grown on 250 soil-types is being studied in a comprehensive scheme of analysis. Uptake of molybdenum by sweet vernal grass is related to molybdenum content of the topsoils and to the nature of the clay minerals, consisting in New Zealand mainly of hydrous oxides or allophane formed by weathering of primary minerals. Allophane contains aluminium in 4-co-ordination; molybdate and other anions containing oxygen are strongly held at broken bond sites in the clay and are less readily released to the plant. Molybdenum uptake thus decreases as weathering proceeds: it depends on $p \mathrm{H}$ also in a rather complicated way. In discussion, attention was directed to the large seasonal and other changes in composition of grass that make this kind of study difficult. This subject was treated by R. L. Mitchell, J. W. S. Reith and Isabel M. Johnston in a contribution from the Macaulay Institute. In Scottish soils the most important factor influencing trace-element avail- ability is the drainage status. Under poor drainage conditions the extractable contents of many trace elements in soils are increased and in certain instances, notably cobalt and nickel, there is a corresponding increase in plant uptake. Numerous and detailed analyses of plants had shown such large changes in mineral content at different times of sampling that it now seemed that analysis of soil would prove a better guide to long-term plant content, provided suitable extractants could be found. For this purpose, ethylenediamine tetraacetic acid (EDTA) may be more useful than acetic acid. A lively discussion ensued regarding the composition and analysis of pasture, which depends not only on soil but also on the proportion of grass to clover. It was mentioned that when pasture is deficient in cobalt the ruminant derives little or no benefit from soil ingested with the fodder.

Having in mind the Long Ashton work on factors involved under the general heading of soil acidity, E. G. Hallsworth, E. A. N. Greenwood and Jane Auden had grown clover, lucerne and lupin in sand and water cultures to study their reactions to low calcium- and high manganese- and aluminium-levels and had found serious restriction to growth in plants showing no toxicity symptoms. In experiments with subterranean clover, growth was restricted when copper was supplied at a low level, but the injury was not otherwise conspicuous; by increasing the copper supply a three-fold increase in dry matter production was obtained. With low levels of copper, phosphorus and molybdenum the plants were perfect miniatures. This effect was not confirmed in a later experiment: the discrepancy is ascribed to climatic conditions, in that symptoms of toxicity or deficiency are most evident when plants are growing vigorously.

A. Thompson's paper on the trace-element contents of herbage plants was presented by Mr. Brynmor Thomas. Supplementing earlier reports, analytical data were given for eight grasses, four legumes and four herbs from Cockle Park; hand-picked specimens of eight herbage plants from plots treated with fertilizers and manures for fifty years showed no large differences in their content of copper or cobalt. Samples from the Palace Leys hay plots showed differences in trace-element content that are ascribed mainly to differences in botanical composition. It cannot be assumed that minerals in fodder are wholly or uniformly available to the animal; for anæmic rats grasses are a better source of iron than legumes or herbs, but all three are inferior to ferric chloride. Aluminium exceeding 200 p.p.m. of the dry matter indicates contamination with soil. There was some discussion on differences in manganese between $A$. 'Thompson's analyses and those of R. L. Mitchell. It was noted by E. A. N. Greenwood that variation in manganese content of lucerne at Sutton Bonington had been traced to variation in illumination.

H. A. Robertson and A. W. J. Broome recorded that injection of thyroxine (four sheep) was followed by a rise in the level of blood sugar and rapid respiration with a slow return to normal, while dosing with thiouracil (two sheep) produced a notable fall in the level of blood sugar and apparently a less slow recovery. There was an inverse change in blood cholesterol. No change was observed in one sheep receiving gradually increasing injections of DNOC. It is inferred that blood-levels of copper depend on activity of the thyroid gland, which affects the basal metabolic activity. In discussion it was noted that 
both thyroxine and thiouracil form complexes with copper.

C. F. Mills's paper on dietary factors influencing copper utilization by the animal was presented by Dr. D. P. Cuthbertson. The greater part of the copper in herbage is in the form of fairly stable organic complexes. Copper in herbage, and in aqueous extracts made from herbage, is more readily available to rats than an equivalent amount of cupric sulphate : the copper complexes present in the extract are not decomposed at ranges of acidity such as occur in the gastric contents of the rat; nor are they decomposed in the digestive tract of the sheep but seem to be absorbed intact. 'The lower availability of ionic copper may be ascribed to the formation of insoluble compounds. Discussion followed regarding conflicting findings with swayback in sheep. It was noted that in animals excess zinc reduces the activity of eytochrome-c oxidase, whereas copper restores it ; in micro-organisms molybdenum has a similar effect to zinc, and the molybdenum-copper interrelationship therefore seemed worth studying in animal enzyme systems.

Copper nutrition in ruminants was further discussed in a paper by Ruth Allcroft and Gwyneth Lewis, who observed that copper deficiency in cattle and sheep in the United Kingdom occurs on pastures with an apparently normal or even high copper content. This is in contrast to parts of Australia and New Zealand, where the disorder is regarded as a simple copper deficiency associated with a low copper content of pastures-usually less than 5 p.p.m. Observations in the United Kingdom indicate the presence of other factors in the herbage which interfere with the utilization and storage of copper in the animal. Australian work has shown that a high molybdenum intake can limit liver copper storage in sheep and cattle, and that the inorganic sulphate content of the diet influences the effect of molybdenum. Evidence obtained so far indicates that the copper, molybdenum and inorganic sulphate contents of the food are not the only factors concerned in the occurrence of copper deficiency in ruminants in Britain. Some of the complexities of copper metabolism were discussed and the possible danger of over-supplementation with copperized mineral mixtures was pointed out. E. J. Butler commented on the gross disparity of pathological symptoms associated with copper deficiency; he agreed that low copper content in pasture does not always lead to swayback. H. A. Robertson mentioned a flock of sheep which was healthy in spite of low levels of blood copper. J. W. S. Reith said there were areas in north-eastern Scotland where crops had responded to application of copper, but animals showed no deficiency in spite of the low level of copper in the pasture.

Classical examples of cobalt deficiency occurring in Connemara were reported by L. B. O'Moore. The disorder occurs with cattle grazing on a calcareous sand of the coastal area and with sheep, especially with recently weaned lambs, pastured on certain acid peats in the inland hill area. On the same peats, cattle are liable to suffer aphosphorosis. The traditional way of avoiding these troubles is to move stock to different grazing areas. However, fortnightly drenching with cobalt sulphate is effective in the coastal sand-blown pastures; top dressing with cobalt is advocated for acid peat land.

A. D. Osborne has found a moderate degree of cobalt deficiency in some parts of north Herefordshire. No severe symptoms appear, but male lambs gain weight more rapidly when given a fortnightly drench of cobalt sulphate; female lambs benefit less from the treatment. In discussion, J. B. E. Patterson noted that the subclinical deficiency is of financial importance to the farmer. The investigation has been difficult, since analytical data for soil and for pasture do not give a clear picture : limits found acceptable elsewhere are not satisfactory here.

Confirming observations in the United States, D. B. Bellis and J. McL. Philp, by adding zine to the dry feed of 8-16-week-old pigs, obtained spectacular cures of parakeratosis, a severe disorder of the skin accompanied by reduced growth. In discussion, it was asserted that the syndrome is mainly due to excessive amounts of calcium carbonate incorporated in proprietary pig feeds; the diet quoted by the authors is high in calcium and low in phosphorus. Work is being continued with a range of calcium/phosphorus ratios.

On April 12, symposium members visited the Long Ashton Research Station and the University of Bristol Veterinary Laboratory at Langford and the artificial insemination unit of Horlicks Farms and Dairies, Ltd. The symposium was organized jointly by the Agriculture Group and the Bristol Section of the Society of Chemical Industry. The organizers owed a particular debt to Prof. T. Wallace and his colleagues for the success of the meeting. The papers and discussions of the symposium will appear in a supplementary issue of the Journal of the Science of Food and Agriculture later this summer.

\section{SEMICONDUCTORS}

$\mathrm{T}$ HE subject of the Spring (1956) Meeting of the Physical Society, organized with the assistance of British Thomson-Houston, Ltd., was "Semiconductors". The report* of the meeting has now, a little belatedly, been published; it contains all but one of the twenty-three papers read, but not the discussions.

Prof. N. F. Mott opened the meeting with his ideas on the transition to metallic conduction via impurity states in a semiconductor. He sought to show that in an array of monovalent atoms, the overlapping of the wave functions of adjacent atoms, though making electron transfer possible, does not necessarily lead to freely mobile carriers. He contested the assumption that an array of singly charged centres in a semiconductor, containing only donors or only acceptors, can be treated as a half-filled band. Confirmation of his prediction, that transition to metallic conduction with increase of concentration of monovalent dissolved atoms will be sudden, may have to await a sample of a semiconductor with regularly spaced donors or acceptors.

Another speaker introduced the idea of a 'semiconductor bond'. It does not exclude one $(A)$ of the two atoms of a compound $A B$ having incomplete $s$ - and $p$-orbitals, provided there is no bonding together of the $A$ atoms. Some predictions of new semiconducting compounds were made, based on a simple relation between the number of valence electrons per molecule, the number of atoms of the molecule lying in Groups IV-VII and any bonding between these atoms.

* Report of the Meeting on Semiconductors held by the Physical Society, in collaboration with British Thomson-Houston, Ltd., Rugby, in April 1956. Pp. 1 